\title{
TUNGAU DEBU RUMAH DI KELURAHAN TAAS KECAMATAN TIKALA KOTA MANADO
}

\author{
Kristin R.Walangare \\ J.S.B.Tuda \\ J.Runtuwene
}

\author{
Bagian Parasitologi Fakultas Kedokteran Universitas Sam Ratulangi \\ Email: Rahel190@gmail.com
}

\begin{abstract}
House dust mite (HDM) is one of the insects found in the dust. Various studies of allergy to house dust around the world shows that the HDM has an important role in trigger allergic reactions such as asthma, atopic dermatitis and allergic rhinitis. Village Taas is a potential area for the deployment of HDM. The purpose of this study to determine the type and density of HDM. The research was conducted in the Village Taas Sub-district Tikala Manado City. The research method used is descriptive survey with a cross-sectional study. Dust samples taken from the area of the meter ${ }^{2}$ the living and sleeping houses, and then examined under a microscope to count the number of HDM to determine density. House dust mites are found, made preparations and identified according to the key M J.Colloff et al. From the examination of 77 houses, it was found that the HDM acarus spp types most commonly found in the living room (35.18\%) and bedroom (36.66\%). Density of HDM in the Village Taas classified as very low at 16 TDR / gram of dust the living room and 19 TDR / gram of dust in the bedroom.
\end{abstract}

Keywords: Density, Parasitology, house dust mites

\begin{abstract}
Abstrak: Tungau debu rumah (TDR) adalah salah satu serangga yang terdapat dalam debu. Berbagai studi tentang alergi terhadap debu rumah di seluruh dunia menunjukan bahwa TDR mempunyai peran penting dalam pencetus timbulnya reaksi alergi seperti asma, dermatitis atopik dan rhinitis alergika. Kelurahan Taas merupakan daerah yang potensial bagi penyebaran dari TDR. Tujuan penelitian ini untuk mengetahui jenis dan kepadatan TDR. Penelitian ini dilakukan di Kelurahan Taas Kecamatan Tikala Kota Manado. Metode penelitian yang digunakan ialah survey deskriptif dengan pendekatan cross-sectional. Sampel debu diambil dari area satu meter ${ }^{2}$ pada ruang tamu dan ruang tidur rumah penduduk, kemudian diperiksa dibawah mikroskop untuk dihitung jumlah dari TDR guna mengetahui kepadatan TDR. Tungau debu rumah yang ditemukan, dibuat preparat dan diidentifikasi sesuai kunci M J.Colloff et al. Dari pemeriksaan 77 rumah, ditemukan bahwa TDR jenis acarus spp yang paling sering ditemukan pada ruang tamu (35,18\%) dan ruang tidur (36,66\%). Kepadatan dari TDR di Kelurahan Taas tergolong sangat rendah yakni 16 TDR/gram debu ruang tamu dan 19 TDR/gram debu ruang tidur.
\end{abstract}

Kata kunci: Kepadatan, Parasitologi, Tungau debu rumah

Salah satu serangga yang terdapat dalam debu adalah Tungau debu rumah (TDR). Tungau debu rumah paling sering ditemukan pada debu dari rumah yang lembab, kasur kapuk, bantal, guling, karpet serta perabotan rumah yang lain. ${ }^{1-24}$ Dapat dikatakan bahwa tidak ada rumah tanpa TDR. ${ }^{1}$

Tungau debu rumah meskipun kecil dan sulit dilihat dengan mata telanjang, 
dapat menjadi masalah yang serius bagi kesehatan manusia. Barbagai studi tentang alergi terhadap debu rumah di seluruh dunia menunjukkan bahwa TDR mempunyai peran penting dalam pencetus timbulnya reaksi alergi seperti asma, dermatitis atopik, dan rhinitis. Bagian tubuh TDR yang bisa menjadi alergen yaitu kutikula, organ seksual dan saluran pencernaan serta TDR yang sudah mati serta tinjanya merupakan alergen yang potensial. ${ }^{1-24}$ Sekitar $4 \%$ populasi manusia menunjukkan alergi terhadap TDR. ${ }^{2}$

Penelitian di Jakarta pada tahun 2000 melaporkan bahwa $81,73 \%$ penderita asma dan rhinitis alergi terhadap spesies ini. $^{3}$ Laisina dkk melalui penelitiannya di Manado pada tahun 2005 mendapatkan hasil bahwa terdapat hubungan yang erat antara penggunaan karpet dalam rumah dengan kejadian asma pada anak. ${ }^{4}$ Hasil penelitianpenelitian terdahulu diketahui bahwa alergen pencetus timbulnya gejala rhinitis alergika terbanyak adalah $\mathrm{TDR}^{5}$ tidak hanya itu Sukses hadi dalam penelitiannya menyimpulkan bahwa terdapat hubungan yang positif antara kepadatan TDR per $\mathrm{m}^{2}$ di kasur \& kolong tempat tidur dengan derajad penyakit dermatitis atopik. $^{6}$

Kondisi perumahan di Manado semakin menurun selama periode 2009-2010, dilihat dari menurunnya persentase rumah tangga dengan lantai rumah bukan tanah turun dari 93,7 \% menjadi 88,7 \% dan persentase rumah tangga yang menempati rumah dengan dinding permanen (tembok) jumlahnya menurun dari 79,5 \% menjadi 74,2 \%. Kota Manado dilaporkan pada tahun 2010 suhu udaranya mencapai antara $25,8^{\circ} \mathrm{C}$ - $27,0^{\circ} \mathrm{C}$ dengan kelembaban udaranya ratarata $80 \%-87 \% .^{25}$ Berdasarkan hal diatas dapat dikatakan bahwa Kota Manado merupakan tempat yang baik untuk TDR berkembang biak.

Kecamatan Tikala yang merupakan salah satu kecamatan yang ada di Kota Manado. Berdasarkan laporan bulanan Puskesmas Kecamatan Tikala penyakitpenyakit alergi seperti asma dan alergi pada kulit hampir selalu masuk dalam 10 jenis penyakit yang menonjol. ${ }^{26}$
Berdasarkan data-data tersebut sehingga penulis tertarik untuk mencari tahu tentang TDR yang terdapat di Kecamatan Tikala Kota Manado khususnya di Kelurahan Taas, mengingat kondisi perumahan di Kelurahan Taas yang belum terlalu baik. ${ }^{27}$

\section{METODE PENELITIAN}

Metode yang digunakan dalam penelitian ini adalah metode survey deskriptif dengan pendekatan crosssectional, untuk melihat kepadatan TDR dan jenis-jenis TDR yang terdapat di Kelurahan Taas.

Penentuan besar sampel berdasarkan rumus Snedecor Cochran, yaitu 77 rumah yang kemudian dipilih dengan metode simple random sampling.

Alat dan bahan yg digunakan adalah penghisap debu/vakum cleaner (Maximus 300, 400 watt), cawan petri, wadah untuk menyimpan debu, timbangan, kaca obyek dan kaca penutup, mikroskop cahaya \& mikroskop stereo, xylol dan eter, kanada balsam dan alkohol 70 \%. Sampel debu yang diambil dari ruang tamu dan ruang tidur rumah penduduk, dibawa ke laboratorium Parasitologi Fakultas Kedokteran Unsrat untuk diperiksa. Sampel debu ditimbang, kemudian diperiksa dibawah mikroskop untuk menghitung jumlah TDR. Tungau debu rumah yang ditemukan di buat preparat kemudian dilihat dibawah mikroskop untuk mengidentifikasi jenis TDR. Identifikasi jenis TDR berdasarkan kunci Mj Collof et al.

\section{HASIL DAN PEMBAHASAN}

Berdasarkan hasil survei yang dilakukan di Kelurahan Taas Kecamatan Tikala Kota Manado, dari 77 rumah penduduk yang telah diperiksa ruang tamu dan ruang tidur ditemukan 65 rumah positif tungau debu rumah dan 12 rumah yang negatif. Dari hasil penelitian ini pula ditemukan lima jenis spesies Tungau debu rumah yakni Cheyletus spp, Acarus spp Glycyphagus destructor, Dermatophagoides spp dan Tarsonemus spp. 
Tabel 1. Ruang Tamu yang positif Tungau Debu Rumah

\begin{tabular}{|c|c|c|}
\hline JenisTungau Debu Rumah & Jumlah yang positif Tungau & $\%$ \\
\hline Dermatophagoides spp & 18 & 33,33 \\
\hline Glycyphagus destructor & 13 & 24,07 \\
\hline Acarus spp & 19 & 35,19 \\
\hline Cheyletus spp & 2 & 3,7 \\
\hline Tarsonemus spp & 2 & 3,7 \\
\hline Total & 54 & $100 \%$ \\
\hline
\end{tabular}

Tabel 2. Ruang Tidur yang positif Tungau Debu Rumah

\begin{tabular}{|c|c|c|}
\hline Jenis Tungau Debu Rumah & Jumlah yang positif Tungau & $\%$ \\
\hline Dermatophagoides spp & 19 & 31,66 \\
\hline Glycyphagus destructor & 15 & 25 \\
\hline Acarus spp & 22 & 36,66 \\
\hline Cheyletus spp & 3 & 5 \\
\hline Tarsonemus spp & 1 & 1,66 \\
\hline Total & 60 & $100 \%$ \\
\hline
\end{tabular}

Tabel 3. Jumlah keseluruhan Tungau Debu Rumah pada Ruang Tamu

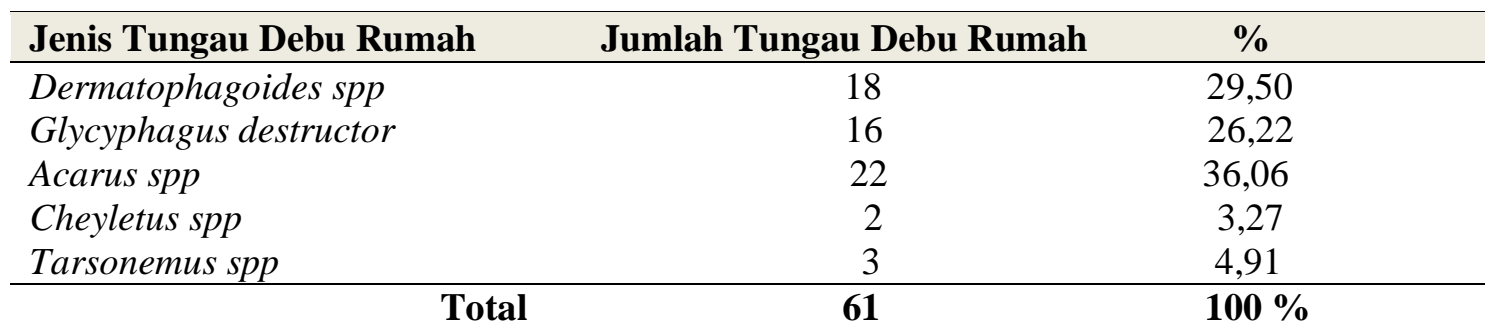

Tabel 4. Jumlah keseluruhan Tungau Debu Rumah pada Ruang Tidur

\begin{tabular}{lcc}
\hline Jenis Tungau Debu Rumah & Jumlah Tungau Debu Rumah & $\mathbf{\%}$ \\
\hline Dermatophagoides spp & 31 & 32,97 \\
Glycyphagus destructor & 21 & 22,34 \\
Acarus spp & 33 & 35,10 \\
Cheyletus spp & 7 & 7,44 \\
Tarsonemus spp & 2 & 2,12 \\
\hline \multicolumn{2}{c}{ Total } & $\mathbf{9 4}$
\end{tabular}

Dari Tabel 1 terlihat bahwa Tungau debu rumah jenis Acarus spp yang mempunyai persentasi terbesar ditemukan pada ruang tamu, serta jenis Cheyletus spp dan Tarsonemus spp merupakan Tungau debu rumah dengan presentasi paling sedikit ditemukan pada ruang tamu.
Dari Tabel 2 terlihat bahwa Tungau Debu Rumah jenis Acarus spp yang mempunyai presentasi terbesar ditemukan pada ruang tidur, serta jenis Tarsonemus spp merupakan Tungau debu rumah dengan presentasi paling sedikit ditemukan pada ruang tidur. 
Dari Tabel 3 terlihat bahwa Tungau Debu Rumah jenis Acarus spp yang paling banyak ditemukan dari keseluruhan Tungau Debu Rumah pada ruang tamu dan jenis Cheyletus spp merupakan tungau yang paling sedikit ditemukan.

Dari Tabel 4 terlihat bahwa Tungau Debu Rumah jenis Acarus spp yang paling banyak ditemukan dari keseluruhan Tungau Debu Rumah pada ruang tidur dan jenis Tarsonemus spp merupakan tungau yang paling sedikit ditemukan.

Dari kelima spesies yang ditemukan, TDR jenis Acarus spp yang paling sering ditemukan pada ruang tamu sedangkan Cheyletus spp dan Tarsonemus spp mempunyai persentasi terendah. Begitu pula dengan ruang tidur, TDR jenis Acarus spp mempunyai presentasi tertinggi dan Tarsonemus spp merupakan TDR yang mempunyai persentasi terendah. Oleh karena hasil tersebut, sehingga dapat dikatakan bahwa frekwensi tertinggi TDR di kelurahan Taas kecamatan Tikala kota Manado adalah jenis Acarus spp. Hal ini sangat berbeda dengan penelitialn-penelitian sebelumnya di Eropa, North America, ${ }^{1}$ Singapura Honolulu Hawaii ${ }^{7}$ dan Thailand ${ }^{8}$ yang menyatakan TDR jenis Dermatophagoides spp yang paling sering ditemukan. Perbedaan ini mungkin terjadi oleh karena perbedaan iklim antara Indonesia dan Negara-negara tersebut. Penelitian dari Aulung dkk di Jakarta menemukan frekwensi sebaran tertinggi adalah TDR jenis Glycyphagus destructor kemudian Cheyletus eruditas. ${ }^{9}$ Perbedaan hasil dari penelitian ini dengan penelitianpenelitian sebelumnya mungkin terjadi akibat perbedaan suhu dan kelembaban. Tungau debu rumah jenis Dermatophagoides spp dan Glycyphagus spp membutuhkan suhu dan kelembaban yang optimal yaitu $25^{\circ} \mathrm{C}$ dan kelembaban 80\%. Sedangkan TDR jenis Acarus spp lebih memungkinkan untuk tumbuh baik pada suhu $23^{\circ} \mathrm{C}$ dan kelembaban $87 \%{ }^{9}$ Keterbatasan dari penelitian ini adalah peneliti tidak sempat mengukur suhu dan kelembaban di Kelurahan Taas Kecamatan Tikala Kota Manado serta alat-alat yang digunakan lebih sederhana.

Dari data jumlah keseluruhan TDR yang ditemukan dari 0,1 gram debu rumah, jenis Acarus spp yang diketahui paling banyak ditemukan di ruang tamu maupun ruang tidur. Hal ini berbeda dengan penelitian dari Sundaru di Jakarta yang menyatakan TDR jenis Glycyphagus yang paling banyak ditemukan. Hal ini mungkin disebabkan oleh perbedaan suhu dan kelembaban. ${ }^{10}$

Dari data hasil penelitian ini juga didapatkan hasil yang menyatakan ruang tidur lebih sering ditemukan TDR (Tabel 2) dan lebih banyak jumlah TDRnya (Tabel 4) dibandingkan dengan ruang tamu (Tabel 1 dan Tabel 3). Hal ini disebabkan karena orang-orang lebih lama berada pada ruang tidur daripada ruang tamu, waktu seseorang di kamar tidur bisa mencapai rata-rata 6-8 jam dan hal ini sangat mempengaruhi populasi dari TDR ini. Populasi dari TDR sangat bergantung dari asupan makanannya dalam hal ini adalah serpihan kulit manusia.

Kepadatan TDR dihitung menggunakan rumus:

$$
\begin{aligned}
& \text { K. TDR } \\
& =\frac{\text { berat debu keseluruhan }}{0,1} \\
& \times \text { jumlah TDR dalam } 0,1 \text { gram debu }
\end{aligned}
$$

Sehingga didapatkan hasil berat debu rerata dari ruang tamu sedikit lebih berat ( 0,2 gram) daripada debu ruang tidur $(0,16$ gram), akan tetapi kepadatan TDR permeter ${ }^{2}$ dari ruang tidur lebih tinggi $(1,95)$ daripada ruang tamu $(1,6)$. Hal ini dapat disebabkan oleh karena perbedaan suhu dan kelembaban dimana suhu dan kelembaban pada ruang tidur relatif lebih tinggi daripada ruang tamu serta kebanyakan orang menghabiskan 6-8 jam di ruang tidur dimana hal ini sangat mempengaruhi asupan makanan dari TDR ini sendiri. Jika dibandingkan dengan sumber lain, dapat dilihat perbedaan dari kepadatan yang sangat jauh. America college of allergy, astma and immunology menyatakan dalam satu gram debu rumah dapat ditemukan jumlah TDR berkisar pada 100-500 TDR. ${ }^{11}$ Penelitian di Malaysia menemukan bahwa dalam 1 gram debu rumah dapat ditemukan \pm 10.000 TDR. $^{7} \mathrm{Dr}$ 
Nadia Aly El-Dib dari Eropa yang merupakan Profesor sekaligus kepala bagian dari unit diagnostik dan penelitian bagian parasitologi di Universitas Kairo menyatakan bahwa dalam satu gram debu rumah (1/2 sendok teh) terdapat 1000 tungau debu rumah. ${ }^{1}$ Jika hasil penelitian ini dikonfersi ke gram maka kepadatan pergramnya hanya 16 TDR pada ruang tamu dan 19 TDR pada ruang tidur. Hal ini dapat disebabkan oleh karena kebiasaan masyarakat kota Manado yang mayoritas Kristen untuk membersihkan seluruh rumah dalam hal ini termasuk juga menjemur kasur dan sofa, mengelap perabotan, mencuci barang-barang dalam bentuk kain, dan mengepel lantai yang dilakukan pada saat mendekati perayaan natal dan tahun baru. Pengaruh dari pembersihan ini pula dapat dilihat pada berat debu yang didapat pada setiap ruangan yang hanya sedikit jumlahnya. Bisa juga hal ini disebabkan oleh perbedaan dari metode pengambilan debu serta alat yang dipakai untuk pengambilan debu tersebut.

\section{SIMPULAN}

Frekwensi tertinggi dari jenis TDR di kelurahan Taas kecamatan Tikala kota Manado adalah jenis Acarus spp dan kepadatan TDR di kelurahan ini tergolong sangat rendah.

\section{UCAPAN TERIMA KASIH}

Terima kasih kepada Dr. dr. J. S. B. Tuda, MKes, SpPar(K) sebagai penguji 1 sekaligus pembimbing 1 , dr. Runtuwene sebagai penguji 2 sekaligus pembimbing 2, dr. V. D. Pijoh, MKes sebagai penguji 3 dan kepada semua pihak baik secara langsung atau tidak langsung telah menimbulkan ide untuk penulis sehingga artikel ini terselesaikan.

\section{DAFTAR PUSTAKA}

1. EL-Dib NA. House dust mites - what might a mite do ?. Vol.II. Cairo: EOLSS; 2002.
2. Sembel DT. Entomologi kedokteran. Widiyatmoko J, editor. 1 ed. Yogyakarta: ANDI; 2009. p.189-191.

3. Natadisastra D, Agoes R. Parasitologi kedokteran ditinjau dari organ tubuh yang diserang. Jakarta: EGC; 2009. p.345-46,40001.

4. Laisinan AH, Takumansang D, Wantania JM. Faktor risiko kejadian asma pada anak sekolah dasar di kecamatan wenang kota manado. Sari Pediatri. 2007; 8: 299-304.

5. Utama DS. Hubungan antara jenis aeroallergen dengan manifestasi klinis rhinitis alergika. Tesis. Semarang: Universitas Diponegoro; 2010.

6. Hadi S. Hubungan kepadatan tungau debu rumah dengan derajat penyakit dermatitis atopik. Laporan Penelitian. Semarang: Fakultas Kedokteran Universitas Diponegoro; 2002.

7. Nadchatram, M. House dust mites our intimate associates. Tropical Biomedicine 2005;22(1): 23-7.

8. Ichsan ES. Tungau debu rumah yang di isolasi pada rumah penduduk di kelurahan Sario Tumpaan kecamatan Sario kota Manado periode November 2001 - Januari 2002. Manado: Universitas Sam Ratulangi; 2002.

9. Sungkar S. Aspek biomedis tungau debu rumah. Maj Kedokt Indon 2004;54:224-33.

10. Sundaru H. House dust mite allergen level and allergen sensitization as risk factors for astma among student in Central Jakarta. Med J Indones 2006 January-March;15:559.

11. American College of Allergy, Astma and Immunology. Dust Allergy Mangement. Available from: http://www.acaai.org/allergist/allergies/Type s/dust-allergy-information /Pages/default.aspx. Accessed on: 2010.

12. Faiza A. Hubungan antara lama penggunaan kasur kapuk dengan jumlah populasi tungau debu rumah di perumahan PJKA kelurahan Randusari semarang. Skripsi. Semarang: Universitas Diponegoro; 2006.

13. Yudopranoto K. Perbandingan populasi tungau debu rumah pada kasur kapuk dan non-kapuk di perumahan PJKA kelurahan Randusari semarang selatan jawa tengah. Skripsi. Semarang: Fakultas Kedokteran Universitas Diponegoro; 2006.

14. Safar R. Parasitologi kedokteran : protozoologi, helmintologi, entomologi. 
Nurhayati N, editor. 1 ed. Bandung: Yrama widya; 2010.

15. Hadidjaja P. Artropoda sebagai kausa penyakit. Hadidjaja P, Margono SS, editors. Dasar parasitologi klinik. 1 ed. Jakarta: Perhimpunan Dokter Spesialis Parasitologi Klinik Indonesia; 2011. p.332-33.

16. Pika AJ, Cunningham MJ, Lester PJ. Development of dermatophagoides pteronyssinus (acari: pyroglyphidae) at constant and simultaneously fluctuating temperature and humidity conditions. J.Med. Entomol; 2005. p.42(3): 266-69.

17. Podder S, Biswas H, Gupta SK, Saha GK. Life-cycle of house dust mite Dermatophagoides pteronyssinus (Acari: Pyrogylphidae) under laboratory conditions in Kolkata Metropolis. Acarina: India; 2009. p.17 (2): 239-42.

18. Departments of Respiratory Medicine and Allergy, Immunology and Infectious diseases The Children's Hospital at Westmead. House dust mite allergy-what should you do ?. Available from: http://kidshealth.schn.health.nsw.gov.au/site s/kidshealth.chw.edu.au/ files/factsheets/pdf/house-dust-mite-allergy-whatshould-you-do.pdf. Accessed on: Juli 2010.

19. The children allergy team at Southampton General Hospital. Child health information factsheet. Available from: http://www.uhs.nhs.uk/Media/Controlleddoc uments/

Patientinformation/Childhealth/Housedustm ite-patientinformation.pdf. Accessed on: Oktober 2011.
20. Astma Foundation SA. House dust mite. Hilton: The Foundation, 2012.

21. British Allergy Foundation. House dust mite. Available from: http://www.allergyuk.org/downloads//factsh eets/types-of-allergy/House\%20Dust $\% 20$ Mite.pdf. Accessed on: Maret 2012

22. The Astma Foundation. House dust mites. New Zealand: The Foundation, 2012.

23. National Eczema Society. Keeping the house dust mites at Bay-Advice for people with Atopic Eczema. Available from: http://www.eczema.org/uploads/BAhbBlsH OgZmI

noyMDEyLzA5LzEyLzE2XzA1XzAyXzQ wNF9NYWluX0ZhY3RzaGVldF9LZWVw aW5nX3RoZV9Ib3VzZV9EdXN0X01pdG VzX2F0X0JheV9fX0FkdmljZV9mb3JfUG VvcGxlX3dpdGhfQXRvcGljX0VjemVtYS 5wZGY?format=pdf. Accessed on: 2008

24. Sungkar S. Artropoda penyebab alergi dan reaksi toksin. Sutanto I, Ismid IS, Sjarifuddin PD, Sungkar S, editors. Buku ajar parasitologi kedokteran. 4 ed. Jakarta: Balai penerbit FKUI; 2009. p.289-91.

25. Seksi Neraca Wilayah dan Analisis Statistik. Statistic daerah kota manado 2011. Manado: Badan pusat statistic kota manado; 2011.

26. Laporan bulanan data kesakitan kecamatan tikala bulan Juli-September 2012. Manado: Puskesmas Kecamatan Tikala; 2012

27. Laporan bulanan kecamatan tikala bulan september 2012. Manado: Pemerintah Kecamatan Tikala; 2012. 